Галина Афанасьевна Мельниченко - известный российский эндокринолог-исследователь, академик РАН, автор и руководитель фундаментальных и прикладных исследований. Г.А. Мельниченко - один из лидеров создания методологии по организации эндокринологической службы Российской Федерации. Г.А. Мельниченко внесла большой вклад в формирование современных представлений о роли аутоиммунных и йододефицитных состояний в развитии патологии щитовидной железы. Ведущий в России специалист по заболеваниям гипоталамо-гипофизарной системы, орфанным эндокринопатиям, надпочечниковой патологии, синдромам множественных эндокринных неоплазий.

КЛЮЧЕВЫЕ СЛОВА:Галина Афанасьевна Мельниченко; эндокринолог; юбилей; академик РАН.

\title{
ON THE ANNIVERSARY OF GALINA A. MELNICHENKO, ACADEMICIAN OF THE RUSSIAN ACADEMY OF SCIENCES
}

Galina Afanasyevna Melnichenko is a well-known Russian endocrinologist-researcher, academician of the Russian Academy of Sciences, author and head of fundamental and applied research. G.A. Melnichenko is one of the leaders in creating a methodology for organizing the endocrinological service of the Russian Federation. G.A. Melnichenko made a great contribution to the formation of modern ideas about the role of autoimmune and iodine deficiency states in the development of thyroid pathology. Leading Russian specialist in diseases of the hypothalamic-pituitary system, orphan endocrinopathies, adrenal pathology, multiple endocrine neoplasia syndromes.

KEYWORDS: Galina A. Melnichenko; endocrinologist; anniversary; Academician of the Russian Academy of Sciences.

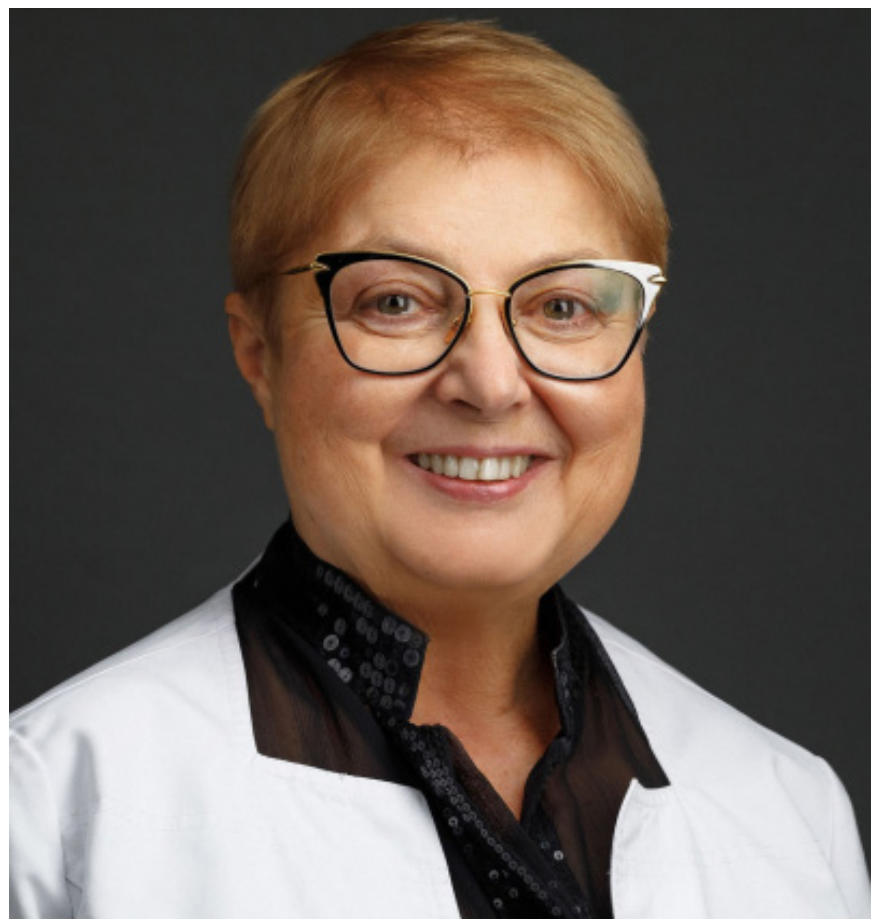

28 ноября все эндокринологи отмечают юбилей известного профессора, академика РАН, вице-президента Российской ассоциации эндокринологов, яркого педагога и главного редактора журнала «Клиническая и экспериментальная тиреоидология» Галины Афанасьевны Мельниченко.

Галина Афанасьевна Мельниченко - один из лидеров создания методологии по организации эндокринологической службы Российской Федерации, ведущий в России специалист по заболеваниям гипоталамо-гипофизарной системы, орфанным эндокринопатиям, надпочечниковой патологии, синдромам множественных эндокринных неоплазий.
В 1972 г. успешно окончила лечебный факультет РГМУ (МОЛГМИ им. Н.И. Пирогова). По окончании ординатуры и аспирантуры работала младшим научным сотрудником Института экспериментальной эндокринологии и химии гормонов АМН СССР (ныне ФГБУ «НМИЦ эндокринологии» Минздрава России). С 1979 по 1987 гг. была ассистентом, а затем доцентом на кафедре внутренних болезней №1 ММА им. И.М. Сеченова (ныне Первый МГМУ им. И.М. Сеченова), где в 1988 г. при 1-м лечебном факультете под руководством профессора Ивана Ивановича Дедова была создана кафедра эндокринологии. С 1992 г. Галина Афанасьевна - профессор кафедры эндокринологии ММА им. И.М. Сеченова, с 2004 г. - член-корреспондент РАМН. В 2011 г. Г.А. Мельниченко присвоено ученое звание академика РАMH, а с 2013 г. - академик РАН, отделение медицинских наук. С 2002 г. Галина Афанасьевна являлась директором Института клинической эндокринологии ФГБУ «НМИЦ эндокринологии» Минздрава России, с 2020 г. по настоящее время - заместитель директора Центра по научной работе.

Галина Афанасьевна - автор и руководитель многих фундаментальных и прикладных исследований в эндокринологии. Основные направления научной деятельности посвящены изучению проблем нейроэндокринной системы, вопросам персонифицированной диагностики и лечения заболеваний гипоталамо-гипофизарной системы, роли полиморфизма пролактина, клиническому значению его изоформ. Г.А. Мельниченко принадлежит разработка подходов к ведению пациентов с синдромом гиперпролактинемии, различными формами эндокринного бесплодия у мужчин и женщин.

Г.А. Мельниченко и ее учениками внедрены технологии диагностики и динамической стратификации папиллярного рака щитовидной железы, показания к использованию 
радиоактивного йода при раке щитовидной железы, развернуты широкомасштабные исследования по мониторингу йододефицитных состояний в Российской Федерации, результаты которых легли в основу Постановления правительства Российской Федерации и Национальной программы «О мерах профилактики заболеваний, связанных с дефицитом йода». Г.А. Мельниченко до настоящего времени является руководителем и научным куратором Национальной программы по скринингу, мониторингу и профилактике йододефицитных состояний в России.

Г.А. Мельниченко и ее ученикам по праву принадлежат приоритет и международное признание в области изучения функциональной системы, регулирующей половые функции у мужчин и женщин, в изучении возможности и разработке методов коррекции репродуктивных нарушений при различных эндокринопатиях, в том числе с использованием методом вспомогательных репродуктивных технологий, а также способы гормональной реабилитации мужчин и женщин в пожилом возрасте.

Академик РАН Г.А. Мельниченко - член Европейских ассоциаций по эндокринологии, эксперт ВАК Российской Федерации по терапевтическим дисциплинам, главный редактор журнала «Клиническая и экспериментальная тиреоидология», заместитель главного редактора журналов «Проблемы эндокринологии» и «Ожирение и метаболизм», руководитель интернет-проекта «Тиронет».

Г.А. Мельниченко создана научная школа - под ее руководством защищено 20 докторских и 40 кандидатских диссертаций. Она - автор более 700 научных публикаций, монографий, руководств, методических пособий, в том числе выдержавшего уже три издания и переведенного на ряд языков стран СНГ учебника по эндокринологии для студентов медицинских вузов. Является куратором разработки более 30 клинических рекомендаций, выпущенных Российской ассоциацией эндокринологии, в том числе в соавторстве с ассоциациями онкологов, радиологов, офтальмологов и др., а также является руководителем исследований, выполняемых по грантам Российского научного фонда, РФФИ.

Галина Афанасьевна Мельниченко является членом Бюро Отделения медицинских наук РАН; членом Президиума Высшей аттестационной комиссии РФ по терапевтическим дисциплинам; почетным членом академии наук Казахстана; вице-президентом Российской ассоциации эндокринологов; членом Европейской ассоциации нейроэндокринологов, Европейской тиреоидологической ассоциации, Международной ассоциации эндокринологов (Endo-society).

Галина Афанасьевна - талантливый ученый, замечательный лектор, неутомимый организатор. Она постоянно находится в творческом поиске и успешно воплощает в жизнь новые идеи, увлекая за собой своих многочисленных учеников. Галина Афанасьевна очень щедрый человек, она охотно делится своими знаниями и временем со всеми, кто приходит к ней за помощью, молодыми врачами, пациентами, коллегами. Галина Афанасьевна для нас, коллег, учеников и студентов, - пример самоотдачи, настойчивости в профессии и жизненного успеха.

За последние годы Галиной Афанасьевной опубликовано третье издание учебника по эндокринологии для студентов, в рамках национального проекта «Здоровье» выпущен цикл рекомендаций для практических врачей. В 2008 г. она награждена орденом Почета Российской Федерации за вклад в науку. В 2011 г. академику РАН Мельниченко Г.А. присвоена первая премия Всероссийского конкурса «Призвание» в номинации «За создание нового направления в медицине». 24 сентября 2021 г. Галина Афанасьевна стала лауреатом премии года Правительства РФ в области образования.

\footnotetext{
Друзья, коллеги, ученики, читатели и редакция журнала «Клиническая и экспериментальная тиреоидология» сердечно поздравляют главного редактора Галину Афанасьевну с юбилеем, желают успехов, здоровья и новых творческих свершений.
}

Рукопись получена: 21.12.2021. Одобрена к публикации: 22.12.2021.

\section{ЦИТИРОВАТЬ:}

К юбилею академика РАН Галины Афанасьевны Мельниченко // Клиническая и экспериментальная тиреоидология. 2021. — T. 17. — №4. — C. 30-31. doi: https://doi.org/10.14341/ket12714

\section{TO CITE THIS ARTICLE:}

On the anniversary of Galina A. Melnichenko, Academician of the Russian Academy of Sciences. Clinical and experimental thyroidology. 2021;17(4):30-31. doi: https://doi.org/10.14341/ket12714 